\title{
Functiescheiding in hoog geautomatiseerde omgevingen
}

\section{J. J. A. Leenaars}

Wat de Wet van Pythagoras is voor wiskundigen is de wet van de functiescheiding voor accountants: beide zijn zeer elementair, zelfs zodanig dat men dikwijls vergeet wat de bewijsvoering is. Sterker nog: voor velen is functiescheiding niet minder dan een axioma.

In dit artikel ${ }^{1}$ wordt vanuit de diepere betekenis van functiescheidingen voor de leer van de administratieve organisatie en de leer van de accountantscontrole aangegeven dat functiescheidingen in een hoog geautomatiseerde omgeving niet alleen een nieuwe inhoud, maar ook een geheel andere dimensie krijgen.

Tevens wordt een methode gepresenteerd, met behulp waarvan functiescheidingen, zoals deze de facto in hoog geautomatiseerde omgevingen zijn geïmplementeerd, zichtbaar kunnen worden gemaakt. Onder een hoog geautomatiseerde omgeving wordt een (kantoor)organisatie verstaan, waarin het merendeel der functies die taken waaraan zij hun bestaansrecht ontlenen, niet anders dan met behulp van geautomatiseerde systemen kunnen uitoefenen.

\section{Inleiding}

Het zou een misverstand zijn te veronderstellen dat functiescheiding in organisaties is geimplementeerd vanuit de primaire invalshoek controle of beheersbaarheid. Sinds het begin van deze eeuw worden organisaties groter en complexer en vindt steeds verdergaande scheiding tussen eigendom en management plaats. Een logisch gevolg van deze ontwikkeling is dat meer hoog- geschoolde mensen in samenwerkingsverbanden een gemeenschappelijk doel nastreven. Deze mensen vervullen taken, welke taken tot afzonderlijke functies in 'dagvolumes' worden samengevoegd. Van nature vindt hierdoor een bundeling plaats van bijvoorbeeld verkooptaken, administratieve taken en produktietaken.

Deze natuurlijke gang van zaken laat onverlet, dat van deze situatie op dankbare wijze gebruik kan worden gemaakt in de administratieve organisatie en daarmee in de accountantscontrole.

Wanneer we ons de waardenkringloop in gedachten nemen, dient ervoor gezorgd te worden dat een functie niet de gehele waardenkringloop kan beheersen. Het gevaar is hier duidelijk: indien een functie zowel in- en verkoop en het beheer over de geldmiddelen beheerst, dan kan hij op eenvoudige wijze een volledige cyclus uit de registratie van de waardenkringloop weglaten.

Functiescheiding wordt dikwijls gezien als een soort trias politica: het scheiden van rechterlijke, wetgevende en uitvoerende machten. Bij funcLiescheiding vertaalt zich dit in de beschikkende, de bewarende en de registrerende macht. Daarnaast komt men in de literatuur als separate basisfuncties ook wel uitvoeren en controleren tegen.

Opvallend is dat zeer weinig literatuur expliciet stilstaat bij de betekenis van de functiescheiding voor de accountantscontrole. In de rijke literatuur van de jaren zeventig rondom klassiek of modern

J. J. A. Leenaars RA studeerde Bedrijfseconomie en Accountancy aan de Hogere Economische School te Rotterdam, lid van het beleidscomité van de Robeco Groep, belast met de portefeuille financiën en systemen. 


\section{MAB}

vinden we wel vele aanzetten. Belangrijk in dit verband zijn mijns inziens vooral het onderscheid tussen vervangbare en onvervangbare interne controle en het in functiescheiding tot stand komen van onafhankelijke deelregistraties welke later op gelijkheid kunnen worden getoetst.

In 1975 ziet NIvRA-geschrift 13 'Automatisering en Controle deel 3: de invloed van de geautomatiseerde gegevensverwerking op de accountantscontrole' het licht. De gekozen benadering laat zich het beste karakteriseren als het doortrekken van functiescheiding tot in de geautomatiseerde systemen, hetgeen het beste met een voorbeeld kan worden geadstrueerd (zie figuur 1).

Figuur 1: Doortrekken van functiescheiding tot in de geautomatiseerde systemen

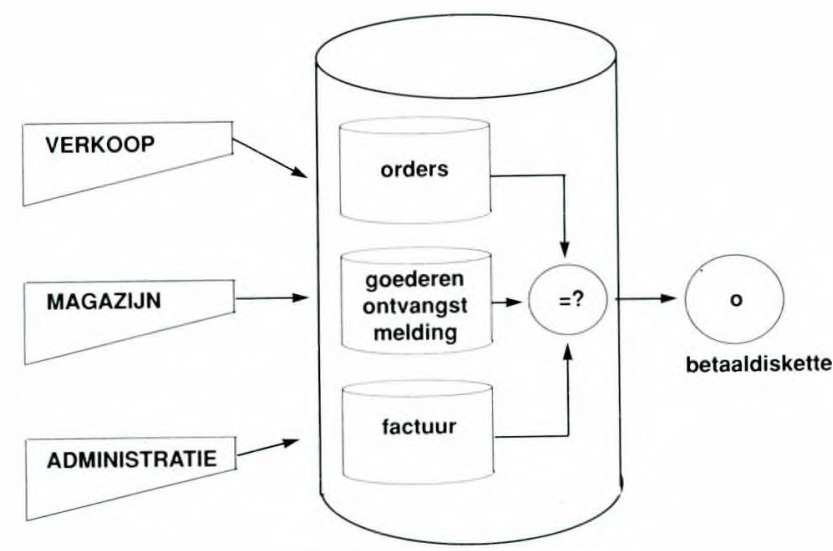

In dit voorbeeld registreert de inkoper een order, worden ontvangen goederen door een magazijnmeester aan het systeem gemeld en worden door de financiële administratie de ontvangen facturen in het systeem gebracht. De computer vergelijkt orders, goederenontvangstmeldingen en facturen, waarna bij gelijkheid de betaling automatisch wordt verzorgd.

Deze gedachtengang heeft breed ingang gevonden in zogenaamde status-gebaseerde systemen waarin verschillende functies met behulp van terminals de administratieve rondgang van goederen, diensten en dergelijke begeleiden.

De gedachte uit NIvRA-geschrift 13 bevat evenwel een majeure tekortkoming: ze gaat ervan uit dat de oorspronkelijke functiescheiding tussen beschikken (de inkoper), bewaren (de magazijnmeester) en registreren (de financiële administratie) ook in hoog geautomatiseerde omgevingen blijft bestaan.

Voordat wordt ingegaan op de in de vorige zin besloten suggestie, namelijk dat er in hoog geautomatiseerde omgevingen wel degelijk iets wijzigt in deze oorspronkelijke functiescheidingen, zet ik het belang van functiescheiding nog eens puntsgewijs op een rij:

1 De centrale doelstelling van de administratieve organisatie en interne controle is de waarheidsgetrouwe registratie van activiteiten die uitmondt in een periodieke eindverantwoording. Deze verantwoording wordt opgebouwd uit in functiescheiding gecreëerde deelverantwoordingen.

2 Onder functiescheiding wordt hier verstaan het primair op basis van doelmatige arbeidsverdeling (specialisatie of differentiatie) toedelen van taken en/of activiteiten over verschillende functies.

3 Slechts in uitzonderingsgevallen zal de doelmatige arbeidsverhouding geen primaat verkrijgen. Zulks zal het geval zijn daar waar sprake is van excessief risico, bijvoorbeeld veiligheid in een kerncentrale, een erg groot gevaar voor directe onttrekking van geldmiddelen, bijvoorbeeld bij banken en bij in de publieke opinie zeer gevoelig liggende ondernemingen.

4 Functiescheidingen hebben voor de interne en de accountantscontrole alleen betekenis, indien sprake is van gescheiden verantwoordelijkheden; deze impliceren in zekere zin tegengestelde belangen.

5 Tegengestelde belangen zijn aanwezig, indien een voordeel voor de ene functie zich laat vertalen in een nadeel voor een andere functie, hetgeen niet per se betrekking hoeft te hebben op mogelijke directe financiële belangen.

6 Wil een dergelijk tegengesteld belang van betekenis zijn voor de interne controle en de accountantscontrole, dus wil het voordeel voor de ene functie dat vertaald kan worden in het nadeel voor een andere functie betekenis hebben, dan dient dit voordeel respectievelijk nadeel te kunnen worden vastgesteld. 


\section{MAB}

\section{Het effect van hoog geautomatiseerde omgevingen}

Laat ons een eenvoudig systeem in een klassieke en in een hoog geautomatiseerde omgeving naast elkaar zetten en ons daarna afvragen wat de principiële verschillen met betrekking tot functiescheiding zijn.

In een groothandel waar artikelsgewijze voorraadadministratie plaatsvindt, zal de klassieke functiescheiding tussen de bewarende, beschikkende en registrerende functie als volgt worden geïmplementeerd: afdeling verkoop (de beschikkende functie) geeft de afdeling magazijn (de bewarende functie) opdracht tot het afgeven van een aantal op een verkoopbon genoteerde artikelen. Een kopie van deze bon gaat rechtstreeks naar de voorraadadministratie (de registrerende functie) die aan de hand van deze kopieën de uitgaande zijde van de kantoorvoorraadadministratie bijhoudt. De inkomende zijde van deze kantoorvoorraadadministratie wordt bijgehouden aan de hand van inkomende facturen.

In een hoog geautomatiseerde omgeving vindt een en ander als volgt plaats: afdeling verkoop (de beschikkende functie) toetst op een terminal een verkooporder in, in een daarvoor beschikbaar staand verkoopsysteem. Op een lokale printer van de afdeling magazijn (de bewarende functie) worden pick-opdrachten geprint. Nadat deze afdeling magazijn de goederen heeft opgehaald (en bijvoorbeeld aan de afdeling expeditie heeft overgedragen), geeft de afdeling magazijn in het systeem aan dat de betrokken verkoopbon is uitgeleverd. Op grond van deze informatie wordt door het systeem tevens de voorraadadministratie direct bijgewerkt.

Het in het oog springende verschil tussen de klassieke en de hoog geautomatiseerde omgeving is dat de onafhankelijke registrerende functie (de administratie) is overgenomen door de computer. Het voorbeeld zou met vele documenten kunnen worden uitgebreid, bijvoorbeeld uitgaande facturen en expeditie- of vrachtbescheiden.

Meer generiek speelt het volgende. Steeds meer in de klassieke situatie door mensen uitgevoerde activiteiten worden door de computer (door pro- gramma's) overgenomen. Dit leidt onherroepelijk tot het verdwijnen van menselijke functies. Overblijvende taken worden gehergroepeerd in resterende menselijke functies, waarbij functievermenging van beschikkende en registrerende taken in één functie tot de reële mogelijkheden behoort: immers slechts in uitzonderingsgevallen zullen doelmatige arbeidsverhoudingen niet het primaat verkrijgen.

In geautomatiseerde systemen wordt ernaar gestreefd redundantie zoveel mogelijk te beperken. Dit betekent dat in functiescheiding gecreëerde deelverantwoordingen voor zover deze geautomatiseerd zijn, weinig bestaansrecht hebben: registratie vindt eenmalig plaats. In het voorbeeld speelt het fenomeen dat de registrerende functie (de administratie) niet langer zelfstandig een deelverantwoording (de kantoorvoorraadadministratie) opbouwt aan de hand van basisdocumenten.

Functiescheidingen die van belang zijn voor de accountantscontrole zijn gebaseerd op tegengestelde belangen. Indien bij deze functiescheidingen sprake is van het vermengen van functies en het vervallen van in functiescheidingen gecreëerde deelverantwoordingen dient te worden gezocht naar een alternatief. Dit leidt tot functiescheiding met een andere dimensie namelijk functiescheiding tussen mens en computer. Of tussen menselijke en geprogrammeerde functies.

\section{Figuur 2: Het vervallen van functioneel gescheiden} deelregistraties door integratie

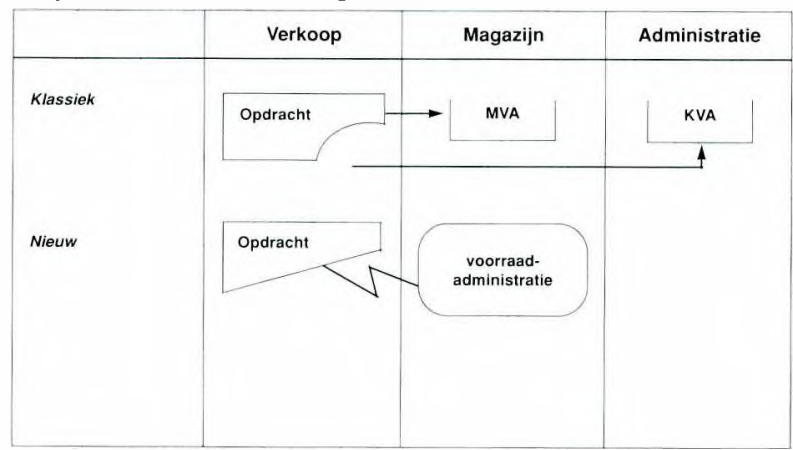

Wat meer technisch vertaalt zich dit in het door functies enerzijds exclusieve en anderzijds gedwongen gebruik van de computer, van pro- 


\section{MAB}

grammatuur om bepaalde taken te kunnen uitvoeren waarbij tevens de registratie door volkomen automatisme wordt gewaarborgd (zie figuur 2).

\section{Functiescheiding tussen menselijke en geprogrammeerde functies}

Waar in het vorige hoofdstuk op relatief filosofische wijze werd betoogd dat functiescheidingen in hooggeautomatiseerde omgevingen een andere dimensie dienen te krijgen om hun betekenis voor de administratieve organisatie en dus voor de accountantscontrole te kunnen behouden, wordt in dit hoofdstuk meer concreet aangegeven op welke wijze het enerzijds exclusieve en anderzijds gedwongen gebruik van de computer, van programmatuur kan worden gerealiseerd. Hierbij zijn steeds twee basisgedachten van belang:

1 een functie kan essentiële taken niet uitvoeren zonder gebruik te maken van de computer. Zo zal bijvoorbeeld een afdeling telefonische verkoop het uitleveren van opdrachten alleen kunnen initiëren door deze opdrachten in de computer in te voeren. Afdeling magazijn accepteert immers alleen pick-opdrachten die op de magazijnprinter worden afgedrukt;

2 functies beschikken over gegevens hetgeen impliceert dat het wijzigen, toevoegen en verwijderen van deze gegevens wordt beperkt.

Enigszins vereenvoudigd kan men stellen dat functionarissen functies vervullen en dat functies met programma's en programma's met gegevens werken (functies werken dikwijls met transacties welke uit meerdere programma's kunnen bestaan; programma's kunnen uit meerdere modules bestaan. Voor het navolgende is dit slechts in zoverre van belang dat een hiërarchie van meerdere niveaus moet worden doorlopen. Voor een principiële beschrijving van de gang van zaken is toevoeging van deze technische complexiteit niet noodzakelijk).

Uit het voorgaande werd al duidelijk dat op een aantal niveaus met zogenaamde cross-reference gegevens moet worden gewerkt:
1 de koppeling tussen functionarissen en functies;

2 de koppeling tussen functies en programma's;

3 de koppeling tussen programma's en gegevens.

Indien we uitgaan van de situatie waarin deze cross-reference gegevens niet op direct interpreteerbare wijze voor de accountant door een systeem worden opgeleverd, dienen deze door de accountant zelf te worden samengesteld. Hiervoor zijn een tweetal hulpmiddelen beschikbaar: voor de koppeling tussen functies en programma's de zogenaamde functieverdeelstaat en voor de koppeling tussen programma's en gegevens een zogenaamde transactie-impactanalyse.

Voordat evenwel de koppeling tussen functies en programma plaatsvindt, dient de koppeling tussen functionaris en functie te worden geverifieerd: de functionaris moet bewijzen dat hij diegene is waarvoor hij zich uitgeeft: het zogenaamde authentication proces. Dit bewijzen dat men is voor wie men zich uitgeeft, geschiedt met behulp van badges, pincodes, passwords en dergelijke. Deze controle wordt volgens de literatuur idealiter opgenomen in zogenaamde toegangscontrolepakketten. In deze pakketten is dan ook de koppeling tussen functie en programma opgenomen.

De functieverdeelstaat en de transactie-impactanalyse kunnen ook worden gebruikt in omgevingen waar deze toegangscontrolepakketten niet zijn geïnstalleerd. De implementatie van toegangscontrolepakketten is een diep in de organisatie ingrijpend gebeuren: eerst op langere termijn mag men de beoogde voordelen realiseerbaar achten.

\section{De functieverdeelstaat}

Hierboven werd al aangegeven dat de functieverdeelstaat de koppeling kan leggen tussen functies en programma's (programma's mag men hier ook lezen als taken, transacties of functies zoals dit begrip wordt gebruikt door automatiseerders). Van belang is ook dat het niet zozeer gaat om het gebruik van gegevens maar veeleer om het wijzigen, toevoegen en verwijderen van gegevens. 


\section{MAB}

Het gemeenschappelijk gebruik van gegevens vraagt om het expliciet aanwijzen van een unieke eigenaar (een functie) van deze gegevens welke verantwoordelijk is voor de inhoudelijke juistheid, volledigheid enzovoort.

De noodzakelijke gegevens voor het samenstellen van de functieverdeelstaat kunnen in de praktijk uit velerlei bronnen worden geput.

Als voorbeelden kunnen worden genoemd: bestanden van toegangsbeveiligingspakketten, tabellen van datacommunicatieprogrammatuur, directories van database managementsystemen, onderliggende databases van datadictionary directory systemen enzovoort.

In figuur 3 is een voorbeeld gegeven van een functieverdeelstaat.

Figuur 3: Een functieverdeelstaat

\begin{tabular}{|c|c|c|c|c|c|}
\hline \multirow{3}{*}{$\begin{array}{l}\text { FUNCTIO- } \\
\text { NARIS }\end{array}$} & \multicolumn{5}{|c|}{ PROGRAMMA (CODE) } \\
\hline & \multirow[t]{2}{*}{ Functie } & \multicolumn{2}{|c|}{$\begin{array}{l}\text { Inbrengen Aanmaak } \\
\text { orderregel vrachtbrief }\end{array}$} & $\begin{array}{l}\text { Inbrengen } \\
\text { klant-naw }\end{array}$ & \multirow{2}{*}{$\begin{array}{r}\begin{array}{r}\text { Inbrengen } \\
\text { krediet } \\
\text { limiet }\end{array} \\
\text { (IKL) }\end{array}$} \\
\hline & & $(\mathrm{BO})$ & $(A V)$ & $(\mid \mathrm{KN})$ & \\
\hline J. Snel & Verkoop & $x$ & & $x$ & \\
\hline P. Stapel & Magazijn & & $x$ & & \\
\hline H. Saldo & Administr. & & & & $x$ \\
\hline
\end{tabular}

Figuur 4: Een transactie-impactanalyse

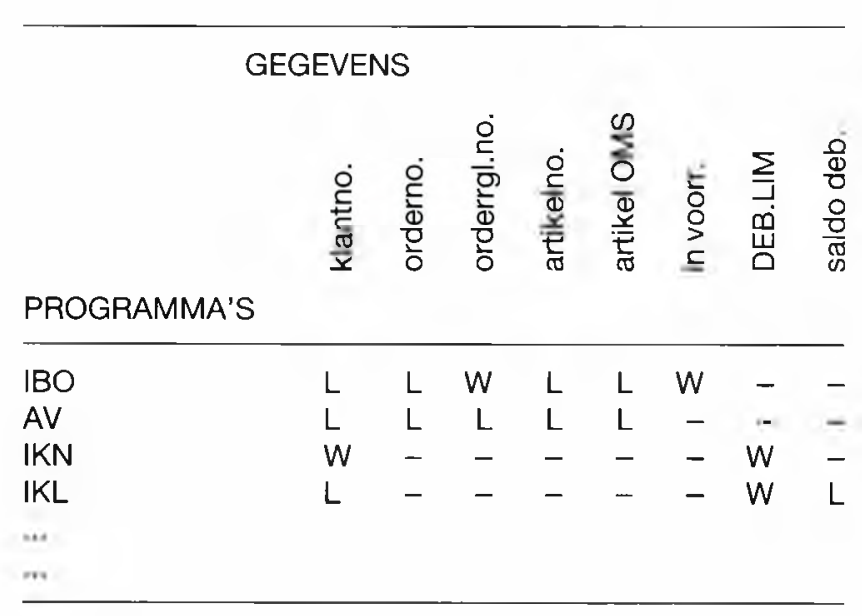

$L=$ Lezen

$W=$ Wijzigen - Toevoegen - Verwijderen
Transactie-impactanalyse

In de transactie-impactanalyse wordt een matrix opgebouwd waarbij per programma wordt aangegeven welke de aard van de invloed is op de onderscheiden gegevens. ${ }^{2}$ Uit figuur 4 blijkt dat bijvoorbeeld het programma IBO (inbrengen orderregels) het klant- en het ordernummer leest, het order-en het regelnummer toevoegt of wijzigt, het artikelnummer van de betrokken orderregel leest, waarna het aantal in voorraad wordt gewijzigd.

Bij een groot aantal gegevens (een doorsnee onderneming kent ongeveer 500 gegevens) en een groot aantal programma's (hetgeen er ook snel enkele honderden zullen zijn) leidt deze techniek tot een onoverzichtelijke matrix. In figuur 5 is aangegeven dat een beter overzicht wordt verkregen indien men per programma alleen de gegevens aangeeft die gewijzigd, toegevoegd of verwijderd worden.

Figuur 5: Een transactie-impactanalyse, waarin van de LEES-bevoegdheid is geabstraheerd

\section{GEGEVENS

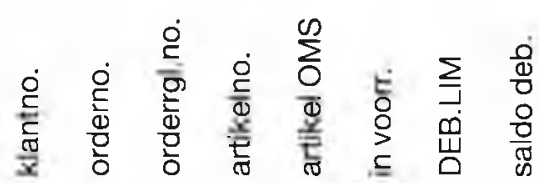

PROGRAMMA'S

\begin{tabular}{|c|c|c|c|c|c|c|c|c|}
\hline IBO & - & - & $W$ & - & - & W & - & - \\
\hline AV & - & - & - & - & - & - & - & - \\
\hline IKN & $w$ & - & - & - & - & - & $W$ & - \\
\hline $\mathrm{IKL}$ & - & - & - & - & - & - & $W$ & - \\
\hline \multicolumn{9}{|l|}{$\ldots$} \\
\hline$\ldots$ & & & & & & & & \\
\hline
\end{tabular}

W $=$ Wijzigen - Toevoegen - Verwijderen

Bovendien zal men in de praktijk een natuurlijke selectie aanbrengen in die gegevens en programma's die voor de te controleren verantwoording van belang zijn. Hierbij dient te worden opgemerkt dat enige voorzichtigheid hier van belang is omdat zowel gegevens als programma's die in eerste instantie niet voor de (financiële) verantwoording van belang lijken door genererende 


\section{MAB}

programma's (programma's die zichzelf opstarten op basis van een bepaald gegeven) kunnen worden beinvloed.

Indien we nu de functieverdeelstaat en de transactie-impactanalyse uit ons voorbeeld combineren dan blijkt dat bijvoorbeeld de programma's IKN (inbreng klant naw) en IKL (inbreng kredietlimiet) beide een beschikking 'wijzigen-toevoegen-verwijderen' hebben over het gegeven debiteurenlimiet. Tevens blijkt dat de afdeling verkoop het IKN programma start en de afdeling administratie het IKL programma.

Concluderend mag worden gesteld dat de beschikkende functie binnen deze organisatie (afdeling verkoop) een debiteurenlimiet kan wijzigen hetgeen een ongewenste functievermenging moet worden geacht.

Indien personeel in de regel frequent wisselende taken uitoefent/van functie wijzigt, zoals bijvoorbeeld bij banken het geval is, wordt een en ander extra gecompliceerd: dit wordt veroorzaakt door het feit dat uit de transactie-impactanalyse kan blijken dat te scheiden functies/taken niet over een beschikking 'wijzigen-toevoegen-verwijderen' van eenzelfde gegeven beschikken, waar de betreffende taken frequent over functionarissen herverdeeld worden. Zo zou bijvoorbeeld moeten worden voorkomen dat een functionaris die een post op een bepaalde toekomstige datum betaalbaar stelt, niet op die toekomstige datum bankrekeningnummers kan wijzigen.

\section{Enige relativerende opmerkingen}

Het in de praktijk kunnen uitvoeren van de in het vorige hoofdstuk genoemde analyses is afhankelijk van de wijze waarop de organisatie van de automatisering is opgezet. Hetgeen enerzijds ziet op de documentatie die wordt bijgehouden en anderzijds op de mate waarin geavanceerde hulpmiddelen ter zake worden ingezet. Er doen zich hierbij twee praktische problemen voor:

1 hoe vindt de accountant binnen de enorme hoeveelheid aanwezige documentatie de voor hem relevante documentatie;

2 hoe stelt de accountant vast dat de aanwezige documentatie de werkelijkheid beschrijft.
Afhankelijk van de mate waarin de documentatie is opgeslagen in een systeem dat een zogenaamde actieve datadictionary is of benadert, zal met name omtrent de laatste vraag aanvullende zekerheid moeten worden gevonden. Een datadictionary is een systeem dat een hoog geautomatiseerde omgeving beschrifft in termen van terminals, bestanden, gegevens, programma's, transacties, gebruikers en koppelingen tussen al deze entiteiten. Een dictionary wordt actief genoemd indien zowel een database managementsysteem of een datacommunicatiesysteem als een gebruiker, bijvoorbeeld de accountant, documentatie uit dezelfde datadictionary ophalen.

In dit artikel wordt de functiescheiding tussen eindgebruikers van geautomatiseerde systemen in kaart gebracht. Tevens is in de functieverdeelstaat en in de transactie-impactanalyse alleen sprake van applicatieprogrammatuur. Mogelijke doorbrekingen van beveiligingen in applicatieprogrammatuur vanuit de zogenaamde systeemprogrammatuur worden met deze methodiek niet ondervangen. Indien dit gevaar van belang wordt geacht, zal het moeten worden gecompenseerd in het vinden van aanvullende zekerheid; dit laatste meer specifiek in het antwoord op de vraag: in hoeverre beschrijft de aanwezige documentatie de werkelijkheid.

Tenslotte wordt steeds uitgegaan van een voorgedefinieerde koppeling tussen programma's en gegevens. De systematiek is derhalve niet geldig, indien eindgebruikers zelf met bijvoorbeeld 'query-talen' relevante gegevens wijzigen, toevoegen en verwijderen. Deze situatie dient uiteraard ook om andere redenen voorkomen te worden.

\section{Noten}

1 Dit artikel is gebaseerd op een studierapport dat onder auspiciën van het NIvRA in 1988 tot stand kwam. De auteur van dit artikel was voorzitter van de CAV werkgroep die de publikatie voorbereidde.

2 In deze paragraaf dient men 'gegeven' eigenlijk te lezen als 'gegevenstype': de 100.000 debiteuren (nummers) zijn gegevens; het debiteurennummer als kenmerk van een debiteur vormt het gegevenstype. 